\title{
Introduction
}

\section{Integral Drama Based Pedagogy as a Practice of Integral Education: Facilitating the Journey of Personal Transformation}

\author{
Liwen MA \\ Associate Professor, Institute of Educational Psychology and School \\ Counseling, Faculty of Education, Beijing Normal University, Beijing, China \\ liwenma@bnu.edu.cn \\ Joseph L. SUBBIONDO \\ Trustee, California Institute for Human Science Encinitas, CA, USA \\ jsubbiondo@gmail.com
}

\begin{abstract}
In this study, we explore the interrelationship of theory and practice by focusing on the practice of Integral Drama Based Pedagogy (IDBP) by tracing its theoretical framework of Wang Yamgming (1472-1529) on its conception, and the theoretical influence of Sri Aurobindo (1872-1950) on its development. In the works of Wang Yangming and Aurobindo, a theory of Integral Education emerges that contributes to an increasing transdisciplinary and interdisciplinary evolution in education in primary, secondary, and higher education. Our intention is to discuss the interrelationship between two educational approaches that are directed toward the student's personal transformation - Integral Education and Integral Drama Based Pedagogy - and to show that their complementarity has had a positive mutual influence. In addition, we include references to the works of Donald Winnicott and his contemporaries on the expansion of IDBP. Lastly, we provide an example of a course component of IDBP, a teaching of the poem "Journey" by Mary Oliver.
\end{abstract}




\section{Keywords}

Integral Education - Integral Drama Based Pedagogy (IDBP) - educational drama drama therapy - Wang Yangming - Sri Aurobindo - "Journey"

\section{Introduction ${ }^{1}$}

Integral Education has become a distinguishing characteristic of twenty-first century higher education due to increasing interest in interdisciplinary and transdisciplinary studies in general, and consciousness studies in particular. This trend is expanding higher education beyond the narrow confines of the traditional disciplines to the extensive areas of integral studies. Moreover, Integral Education is radically changing long-standing perceptions regarding the nature and acquisition of knowledge, as well as the role of colleges and universities (see Sean Esbjörn-Hargens, Jonathan Reams, and Olen Gunnlaugson 2010).

While there are several inspirations for Integral Education, we will consider two: one advanced by Wang Yangming in sixteenth-century China, and another by Sri Aurobindo in twentieth-century India. Aurobindo's model was adapted for U.S. higher education by Haridas Chaudhuri in the mid twentieth century and introduced in China by Xu Fancheng in the late twentieth century. As we shall see, both have had an impact on Integral Drama Based Pedagogy.

Theories and practices are dynamically interrelated in that they often influence the development of the other. For example, a psychological theory can inspire a therapeutic practice; and as the practice evolves, it can bring about revision in the theory. Furthermore, a theory that did not initially influence a practice can enhance the practice, and the practice can advance the theory. In this paper, we explore the interrelationship of theory and practice by examining a theory that inspired a practice and another theory that later influenced the development of the practice. Moreover, we shall see that a practice can help us understand and support a theory. This paper is written in the spirit of the "Reflection-in-Action" movement advanced by Donald Schön and his colleagues at M.I.T. and popularized in his The Reflective Practitioner (1983).

Integral Drama Based Pedagogy (ID BP) is an educational practice developed by Liwen Ma, Professor in Mental Health Education and School Counseling in Graduate Education at Beijing Normal University and co-author of this

1 Cultivating Creativity through Arts-Based Education: Case Studies in Multicultural Contexts. Funded by the International Joint Research Project of Faculty of Education, Beijing Normal University. No. ICER201907. 
paper. IDBP enables her students to transform themselves in discovering their authentic selves by integrating educational and therapeutic drama. Its philosophical thought was initially inspired by Wang; and following its initiation, ID BP has drawn upon Aurobindo's integral theory.

To reflect Aurobindo's theory of integral education, Prof. Ma added the word 'Integral' to 'Drama-Based Pedagogy' in order to accurately describe the course. In addition, the pedagogical strategies and teaching styles of IDвР provide examples of both theories and document the "what" and not only the "how" of Integral Education.

\section{Wang Yangming}

Wang Yangming advanced a theory of integral education that recognized the unity of knowledge and action within a mind-body-spirit approach to education (see Ching 1976, and Ivanhoe 2002). He was born in 1472 in Hangzhou, China. The son of a government official, he received an education centered on Confucian studies that included close readings of Confucius and his leading disciples, especially the fourth-century вс philosopher, Mencius, who taught that knowledge and action were integrated. Wang Yangming was introduced as a young man to Daoism and Buddhism; and while he was intrigued by them, he rejected them in favor of Neo-Confucianism.

Wang Yangming distinguished himself in several areas: he was a prominent statesman, writer, poet, calligrapher, military leader, teacher, and philosopher. While Governor of Jiangxi Province, he was a leading government official and a noted teacher/philosopher. His life and career came to a crisis when he was exiled from 1506-1510 in a remote area of Guizhou Province. The effect of his exile was similar to that of Aurobindo's year-long imprisonment in that both men spent hours in meditation that led to their personal awakening. As we shall see, meditation is an integral component of ID вP.

During his exile, Wang Yangming radically changed his thinking as he determined that human knowledge was innate and that it was integrated into action. He concluded that without knowledge, a person could not act; and without action, one could not know. Years afterwards, he summed up his awareness in his poem:

Everyone has within an unerring compass;

The root and source of the myriad transformations lies in the mind.

I laugh when I think that, earlier, I saw things the other way around;

Following branches and leaves, I searched outside! (IVANHOE, 2009:181) 
For the rest of his life, he maintained that knowledge and action were inseparable. In Wing-tsit Chan's translation of the Ch'uan Xi Lu (The Instructions for Practical Living), he asserted:

Knowledge is the beginning of action and action is the completion of knowledge. Learning to be a sage involves only one effort. Knowledge and action should not be separated (CHAN,1:22B).

He contended that education must be directed toward helping students cultivate their innate knowledge to act authentically. As Youngmin Kim notes,

The English translation of liangzhi is innate knowledge or innate knowing, which suggests that we already possess all the knowledge we need to have. We do not have to spend any time to acquire knowledge. Precisely speaking, we cannot acquire knowledge, for we, as self-sufficient moral agents, already possess it from the very beginning. (KIM, 1997)

After his exile, Wang Yangming returned to Peking and re-established himself prominently in the many areas that he formerly excelled. Bryan Van Norden (2019) summarizes the closing chapter of his life, noting his remarkable ability in many and varied undertakings right up to his death. Norden writes:

Wang Yangming had begun to attract devoted disciples even before his exile to Guizhou, and they gradually compiled the Record for Practice (the anthology of his sayings, correspondence, and dialogues that is one of our primary sources for Wang Yangming's philosophy). It is reflective of Wang Yangming's philosophy that the discussions recorded in this work occurred in the midst of his active life in public affairs. Near the end of his life, Wang Yangming was called upon to suppress yet another rebellion (1527). The night before he left, one of his disciples recorded the "Inquiry on the Great Learning," which was intended as a primer of Wang Yangming's philosophy for new disciples. Wang Yangming put down the rebellion, but his health had been declining for several years, and he died soon afterward (1529).

Like Aurobindo, Wang Yangming held an integral view that "supported transdisciplinary knowledge" as he connected metaphysics, ethics, and philosophical psychology. He envisioned an integrated universe with the human mind as its center: 
Even Heaven and Earth cannot exist without the innate knowledge that is inherent in man. For at bottom Heaven, Earth, form is the clear intelligence of the human mind. Wind, rain, dew, thunder, sun and moon, stars, animals and plants, mountains and rivers, earth and stones are essentially of one body with man. It is for this reason that such things as the grains and animals can nourish man and that such things as medicine and minerals can heal diseases. Since they share the same material force, they enter into one another. (WANG YANGMING, 3:29B-30A)

Wang Yangming has recently been honored in China's contemporary renaissance in spirituality. President Xi Jinping has celebrated his work, and the Peoples Republic of China has enshrined the cave of his exile in Guizhou (see New York Times 10/18/2017).

Sri Aurobindo was born in Calcutta in 1872, educated at Cambridge University, and briefly served as professor of English at the College in Baroda and as principal at Bengal National College in Calcutta. After intense involvement in the liberation of India, he established an ashram in Pondicherry where he wrote extensively on integral consciousness, philosophy, psychology, spirituality, and yoga until his death in 1950 (see Aurobindo, 1997).

Throughout his writings - including The Life Divine (1940), The Synthesis of Yoga (1948), and The Ideal of Human Unity (1950) - Aurobindo explored the nature and evolution of integral consciousness and its relationship to the cosmos and the divine. In his "A Preface on National Education" (1921), he urged India to base its educational reform on an integration of mind, body, and spirit. He pointed out "... it should be clear that the only true education will be that which will be an instrument for this real working of the spirit in the mind and body of the individual and the nation" (1956:16).

Similar to practitioners of IDB P, Aurobindo opposed Indian traditional education based on recitation and information transfer. He insisted the "central aim [of education] is the building of the powers of the human mind and spirit, it is the formation or ...the evoking of knowledge and will and of the power to use knowledge, character, culture ..." (1956:9-10). As we shall see, IDB P not only supports the cognitive values of Aurobindo, but it also substantiates and expands his claims. 
Aurobindo contended that "there are three things which have to be taken into account in a true and living education, the [person]...the nation ... and universal humanity" (1956:13). Pointing out that Western education was "based on an insufficient knowledge of human psychology" (1956:19), he maintained that effective pedagogy, like that in IDBP, was grounded in psychology. The first step in developing a national education system was "finding a system of teaching which shall be natural, easy, and effective" (ibid.). Each student is a unique individual because "Each human being is a self-developing soul and the business of both parent and teacher is to enable and help the child to educate himself, to develop his own intellectual, moral, aesthetic, and practical capacities and to grow freely as an organic being, not to be kneaded and pressured into form like an inert plastic material" (1995:145-146). Like that of IDBP, Aurobindo's goal of education was self-transformation through discovery of one's authentic self. Moreover, he insisted "The system of education which instead of keeping artistic training apart as a privilege for a few specialists, frankly, introduces it as a part of culture no less necessary than literature or science...." (1995:52).

Ten themes (see Subbiondo 2006) recur throughout the works of Wang Yangming, Aurobindo, and proponents of integral education: 1) drawing upon a theory of integral consciousness, 2) integrating spirituality into content, 3) connecting diverse cultural traditions, 4) exploring inner and outer dimensions of life, 5) including contemplative practices, 6) relying on multiple ways of knowing, 7) acknowledging individuals as a part of a collective, 8) supporting transdisciplinary knowledge, 9) honoring experiential learning, and 10) seeking unity in diversity.

\section{Integral Drama-Based Pedagogy (IDBP)}

To trace the history of the development the IDBP, we will outline the teaching strategies of IDBP; note teaching techniques from the course, "Personality and Social Development Counseling"; focus on a class on Mary Oliver's poem "The Journey"; review student reactions to the class; and comment on ID B P's contributions to Integral Education. Our overall rationale is guided by Shön's thesis that he notes in his The Reflective Practitioner (1983): "starting with protocols of actual performance, it is possible to construct and test models of knowing" (Preface).

Inspired by Wang Yangming, Prof. Ma motivates her students to explore the interrelationship of knowledge and actions by affirming that correcting their mistakes and renewing themselves are their most important human activities. 
Her students consider a concept of Wang Yangming that the "unerring compass" of one's innate knowledge effects one's actions. She teaches her students his guiding educational principle, that to know and not to act is not to know.

Students discuss the notion of the whole person, and how they can unify their personalities and social development. They realize that being a whole person is a prerequisite to be an effective teacher. As an integral education course, it helps students learn that their wholeness depends upon a connection between their inner and outer selves. In all ID BP courses, critical thinking and creative expression prepare students to discover their innate knowledge, correct their deviations, and change their behaviors.

Because traditional education is often fixated on external evaluation, IBDP students start their self-inquiry with internal evaluation. Prof. Ma is aware that external evaluation can drown students' inner voices, and they are oblivious to the power of their innate knowledge. It often places too much emphasis on rigid codes of social conduct that limit individual thought, expression, and action. Similar to the teachings of Aurobindo, students seek "unity," not "uniformity."

By strictly following socially acceptable rules, students can suppress the individuality of their critical thinking and expression, becoming afraid to differ from their peers. Prof. Ma contends that traditional education with too much rational positivism, book learning, and autocratic behavior can cause teachers and students to distrust their inner voices and ignore their innate knowledge. Students often jeopardize their vitality and authenticity, finding themselves in a culture of fear that threatens their learning. The systematic depersonalization brought about by traditional education endangers personal and social development as students often suffer overloaded expectations, learning weariness, and psychological issues. Consequently, teachers and students often experience burnout and emotional exhaustion.

Donald W. Winnicott (see Winnicott 1964 and 1971) has significantly influenced the study of psychology and play therapy as well as the development of ID B. He recognized that by living in our bodies, we eventually realize the reality of the external world. For him, the role of the ego, as an aspect of the self, is to organize and integrate experience. In infants, the self represents human potential; and in supportive environments, infants can evolve into their whole selves. A whole person distinguishes between, in Winnicott's words, "Me" and "Not-Me." 
He determined that children recognize and develop themselves through objects; and as babies, they discover transitional objects and separate themselves from their mothers through object identification and mirroring. He recognized that environment is critical for a child's development because a child builds an authentic self only in a supportive environment. Without such an environment, a child creates a false self.

In the past decade, the term "self" has often been used to describe how individuals feel subjectively; and Winnicott placed the sense of "feeling real" at the center of the sense of self. He regarded supportive environments as transitional spaces that enable children to bridge fantasy and reality. These spaces are where children and adults play, perform, and explore; and drama is an integral part of these spaces.

Similar to Winnicott's supportive environment, IDBP creates a safe space for students to discover themselves. It is a psychological space that connects teacher and student and where healing can take place because students can regress to past experiences in games and plays, and where they can relive them in rediscovering and integrating themselves. Through drama, ID BP courses enable students to connect with their inner conscious and unconscious selves; and the courses help students externalize these connections. Students are able to project their feelings, emotions, and thoughts into their roles through movement and language. They also can identify their inner feelings and emotions as well as the cognitive worlds of others by interacting in drama and interpreting their body movements and those of others.

The space between self-projective performances and interpretations of the performances of others allows students to "look and see" as well as to be "looked and seen." According to Winnicott, "Being looked and seen," is essential for human development. He noted that it is the basis of healing because it affirms a person's sense of existence. ID BP provides students with a safe space for self-development, empowering them to touch the unreal and divided parts of the ego, to explore the true self, and to integrate the divided ego. The pathway for IDBP is drama; and as a comprehensive art form, it enables students to externalize their inner feelings and thoughts through physical expressions. The practice of IDBP recognizes that drama is an integral part of people's nature: a position that is compellingly argued by Augusto Boal, especially in Theatre of the Oppressed (1979), Games for Actors and Non-Actors (1992), Desire of Rainbow (1995).

Since 2009, Prof. Ma's principal method of teaching graduate students majoring in mental health education and school counseling has been IDвP; and, to date, nearly 400 students have taken her course. To adapt the course 
to the mental health education program and school counseling program that promote self-development, Prof. Ma teaches various therapeutic approaches, including Rainbow of Desire (Boal, 1995), Playback Theatre (Fox, 1994,1999), and Psychodrama (Moreno, 1953, 1977; Moreno, et al, 2000).

IDBP differs from courses in traditional educational drama in that it has a therapeutic function, and it differs from courses in drama therapy and psychodrama in that it does not focus on treating people with serious mental health problems. The function of IDBP is both educational and therapeutic, standing between traditional educational drama and drama therapy.

IDBP integrates the methods and technologies of educational drama, which is a teaching methodology that has been developed primarily by Dorothy Heathcote and Gavin Bolton as well as by other leading drama practitioners (Bolton,1979; Johnson \& O'Neill, 1984; McCasilin,1987,198o, 200o; O'Neill,1995; Way, 1967). It has been advanced in drama therapy, which is a therapy method using drama (Emunah,1994; Jennings, 1995; Nelson \& Finneran, 2006; Slade, 1954; Schattner \& Courtney, 1981) and in person-centered expressive art therapy (Rogers, 2000, 2004, 2011). IDBP expands the nature of traditional educational drama and increases the healing characteristics. Therefore, it has four attributes: educational, social, artistic, and therapeutic.

IDBP regards people as a combination of physical, emotional, cognitive, spiritual, social and aesthetic dimensions. It focuses on the mind, and it explores the unity of knowledge and action and the development of true self through teaching and learning mediated by drama. Promoting professional development through a teacher's spiritual development is the core value advocated by IDBP in teacher education. The "root" and "shoot" of education are the metaphors of IDBP. It does not focus on the explicit "fruit" (product), but it cultivates and nourishes the "ren" (kernel), which is the core and foundation of human being, namely innate knowledge.

Over the past ten years, IDBP has proven very suitable for students, teachers, and school administrators who wish to engage in self-exploration, selfawareness, self-reflection, and self-integration. The course offers two credits and consists of 32 meetings, each 45 minutes long. Often three meetings are combined into one class session.

In the implementation process of IDBP, there are four organic and structural contents of red, white, purple, and blue; and they serve as metaphorical representation. These four parts form an organic whole, which is integrated and inseparable in the course. 
Red represents the dramatic game which is an active and enthusiastic part that stimulates physical energy, opens body movements, and stimulates intrinsic interest and motivation to participate in the game.

White represents mindfulness and meditation which brings concentration and tranquility to participants. Participants need to concentrate on present body movement experience and inner feelings, and they need to establish a close connection between body movement and inner feelings.

Purple represents the drama process and is a kind of exploration process that relies on the tension of the drama. Participants believe and act as if the drama were true, falling into the immersive drama process because they are motivated to follow the mystery.

Blue represents all that they continue to share in the process of dialogue. It represents the whole process of experience, feeling, reflection, precipitation and sublimation. In reflection, precipitation and sublimation, participants in the creative learning process of the drama will be more profound, and they find their own meaningful development.

\section{A Class in the Course "Personality and Social Development Counseling"}

To illustrate the teaching process of IDBP, we will discuss a class meeting of the course "Personality and Social Development Counseling" that draws upon reading, interpreting, and performing Mary Oliver's poem, "The Journey." The course helps students discover their inner selves, increase their self-awareness, and transform themselves. It is intended for in-service teacher education and teacher training, and it examines the dependence of professional development on spiritual and psychological growth. The course is fully aligned with the mind-body-spirit values of integral education in that it exemplifies one of its principal themes: to explore inner and outer dimensions of life. Students examine the integration of poetry, story, painting, music, and other art forms into drama. Each course is a comprehensive and integrated application of various art forms.

Mary Oliver (1935-2019), a contemporary American poet, wrote about her personal experiences and the relationships between people and nature; and her poems reflect a full range of human emotion. Her belief that a person is an integral part of nature is very consistent with traditional Chinese wisdom as well as aligned with integral education. In her poem "The Journey," Oliver expresses one's inner awakening during external oppression. 
The text of this poem is as follows:

One day you finally knew

what you had to do, and began,

though the voices around you

kept shouting

their bad advice-

though the whole house

began to tremble

and you felt the old tug

at your ankles.

"Mend my life!"

each voice cried.

But you didn't stop.

You knew what you had to do,

though the wind pried

with its stiff fingers

at the very foundations,

though their melancholy

was terrible.

It was already late

enough, and a wild night,

and the road full of fallen

branches and stones.

But little by little,

as you left their voices behind,

the stars began to burn

through the sheets of clouds,

and there was a new voice

which you slowly

recognized as your own,

that kept you company

as you strode deeper and deeper

into the world,

determined to do

the only thing you could do-

determined to save

the only life you could save. 
The "Journey" tells a story of you in the second person narrative. You is experiencing a fierce psychological conflict and struggle. On the one hand, it is the external distracting noise of you's life; and on the other hand, it is the inner voice of you that is overwhelmed. In this struggle, you finally hears you's inner voice, and you breaks through many obstacles; you save you with you's own inner strength; you starts to act; you breaks the shackles; and you creates a new life. This journey illustrates how one transforms and finds oneself, and it offers considerable space to inspire students to project their own experiences on the protagonist you.

While the class is organized in four parts, represented by the colors white, red, and blue, the class is an integrated whole in that the parts flow smoothly together.

In the white part, meditation and mindfulness session of the class, students engage in ten minutes of meditation, followed by standing comfortably and quietly. They relax their spines by bending down as far as they can. Then, they rise up, one by one. This activity clears their minds. Students perform this exercise three times at their own pace, and it quiets their minds, helps the Qi of their bodies run smoothly, and prepares students to participate in the next step.

In the red part, warm up and play, students engage in the game of "action and reaction."The first student goes to the common space, makes a physical gesture; and the second student randomly comes into the space, and reacts to the first student's gesture. Eventually, five people come to play roles; and they jointly construct a picture of a certain significant image. This exercise helps students observe, understand, and respond to others. The process is improvisational and swift, so that it reveals direct feelings and actions in the moment; and as an exercise, students move quickly into the present. Students are expected to be non-judgmental, no matter their interpretations and responses. All expressions are accepted, and each student respects the personal experiences of other students. In the process, students discover considerable differences in understanding each other, and they learn that understanding another requires communication. Lastly, students respond by reflecting on their own thoughts.

In the purple part, process drama activity, students learn and summarize their perspectives in a small segment of freeze frame pictures. They present the meaning of the picture through dramatic elements such as space position, role performance, props, focus, and tension, etc. On the basis of these activities, the class engages in process drama and the material is Oliver's "The Journey." 
In the blue part, students gather together in a circle; and they discuss their thoughts and emotions regarding the poem.

Below is an outline of typical activities:

First, there is an individual reading in which student read the poem privately at their own pace and with their own feelings. In this process, each student gets closer to the poem. Drawing on the words of the poem, students gradually go deeply into the metaphors and become inspired by the poem.

Second, there is a group reading in which students read the poem together, offer their own interpretations at their own pace, and exhibit their own emotions. The intention of this process is to allow students to express their emerging and recessive feelings in public; and in doing so, the poem creates safe place for expression of personal emotion.

Third, in sharing personal stories, students choose another student with whom they are least familiar. The two students share their personal stories that resonate with their interpretations of the poem. This process creates deeper internal connections between the emotions conveyed in the poem and the life experiences of each student. By now, the poem takes on a personal significance for each person.

Fourth, in the activity on group freeze images, the class is divided into groups of five students. According to the group's understanding and discussion of the poem, the poem is divided into several meaning group freeze images. Everyone in the group participates in impromptu and corresponding body movements. For each image of the poem, each student has a corresponding position and role. The students explain in freeze images what they think is the meaning conveyed by the group. As one group displays freeze images, another group reads the poem and displays its own freeze images. While one group is presenting, the other groups are reading the poem in a group. In order for the reading to match the performance, the other groups communicate with the presenting group to learn their interpretations of the poem.

And fifth, discussing and sharing, students sit in a circle and express their feelings and ideas regarding the poem, share stories, construct freeze images, display images, watch freeze images, and read poems for other groups. The students speak in sentences with phrases like "When I see (do)..., I feel..., and I'm thinking of.... "This process reveals the students' reviews and reflections of themselves as actors; and it also serves as dialogue among students about their feelings, internal experiences, and ideas as observers. The process relies on interaction and dialogue among all on what they believe inspires and engages them. 
Prof. Ma's qualitative analysis of students' reactions to the class on "the Journey" provide us with insight regarding the effectiveness of ID BP, in general, and the class on "The Journey" in particular.

When the meaning of the words of "The Journey" are interpreted by the students' embodied movements, the tension in the poem is amplified, lively, and vivid. This becomes most apparent when following their performances of the freeze frames, the students sit in a circle and share their feelings. They tend to use words such as "shock," "determination," "hope," "growth," "fun," and "cooperation." They note that rehearsal and performance bring out one or more of the following related reactions: overwhelmed, restrained, hopeful, and believing.

These reactions are prompted by various aspects of the process.

First, the freeze-frame pictures portray significant body tension caused by opposing movements. For example, protagonists often try to express their forward struggle and yearning; while antagonists, portraying the environmental obstacles try to repress, restrain, and prevent the protagonists from advancing.

Second, cloth materials used by each side of the struggle have strong visual impact as the colors of the cloth play functional and symbolic roles in the performances. By using cloth appropriately, students translate the content, meaning, theme, mood, and atmosphere of the poem. For example, students use purple, black, and red cloth to represent strong, depressing, stressful, and binding external forces; and they use shiny blue cloth to represent starlight; and they use red, green, pink, and white cloth to symbolize light and hope.

Third, the combination of cloth and body movements reinforces impact as the protagonists are typically in between two cloths to indicate that their life is in the gap. Throughout, these color metaphors produce a strong sense of conviction and hope for change. The students consistently say that color gives them a feeling that the group is rising and provides a sense of cohesion, coordination, cooperation, and fulfillment.

Fourth, students mention how much they enjoy collaborating with each other. While students hardly knew each other at the beginning of the class, they find the group activity is very gratifying. As students share their own understanding of the poem through body movements, they inspire each other. They consider this process growth, and they point out that students with personal difficulties often feel the excitement and collaboration of working together. This helps them express themselves by releasing stress and negative emotions.

At the end of the eight-week course, students review and analyze what they wrote regarding each lesson. They sort out keywords to express what they have 
experienced in the course. Lastly, each student presents a monologue with body movement, verbal expression, and interpretation of the process of change.

\section{$8 \quad$ Conclusion}

Our intention in this paper has been to discuss the interrelationship between two educational approaches that are directed toward personal transformation - Integral Education and Integral Drama Based Pedagogy - and to show that their complementarity has had a positive influence on each other. As we have noted, the central themes of integral education reverberate throughout IDвP. In light of this interaction, we conclude the following.

First, theories and practices are interrelated, and each can have an impact on the other at any point in their development.

Second, twentieth-century Integral Education as inspired by Aurobindo can be viewed in light of a fifteenth/sixteenth century Neo-Confucian Movement led by Wang Yangming.

Third, ID BP has been improved by Prof. Ma's contact with Aurobindo's view of Integral Education in that it has acquired another language for describing, discussing, understanding, and improving its practice.

Fourth, IDBP offers teaching strategies and styles that exemplify in depth the theories of Integral Education which currently lack such examples.

Fifth, the current interaction between Integral Education and IDBP provides significant incentive to higher education to advance its transdisciplinary trends into fuller integral models of education.

It is our hope that this paper will encourage others to seek more interrelationships between relevant theories and practices in order to improve our understanding of education and its delivery at all levels - primary, secondary, and college/university. Beijing Normal University's support of Prof. Ma's pioneering work sets an international example of the mutual benefits that can be realized through greater global scholarship and collaboration.

\section{References}

Aurobindo, S. (1995) Sri Aurobindo and the Mother on Education: A New Education for a New Consciousness. Pondicherry, India: Sri Aurobindo Ashram Press.

Aurobindo, S. (1997) Human Cycle, Ideal of Human Unity, War and Self-Determination. Volume 25 of the Complete Works of Sri Aurobindo. Pondicherry, India: Sri Aurobindo Ashram. 
Aurobindo, S., \& Alfassa, M. (1956) On Education. Pondicherry (India); Sri Aurobindo Ashram Press.

Boal, A. (1979) Theatre of the Oppressed. New York: Theatre Communications Group.

Boal, A. (1992) Games for Actors and Non-Actors. New York: Routledge.

Boal, A. (1995) The Rainbow of Desire: The Boal Method of Theatre and Therapy. New York: Routledge.

Bolton, G. (1979) Towards a Theory of Drama in Education. London: Longman.

Ching, J. (Ed.). (1976) To Acquire Wisdom: The Way of Wang Yang-Ming. New York: Columbia University Press.

Emunah, R. (1994) Acting for Real: Drama therapy process, technique, and performance. New York: Brunner/Mazel.

Esbjörn-Hargens, Sean, Jonathan Reams, and Olen Gunnlaugson, eds. 2010. Integral Education: New Directions for Higher Learning. Albany NY: sunY Press.

Fox, J. (1994) Acts of Service: spontaneity, commitment, tradition in the nonscripted theatre. New Paltz, New York: Tusitala Publishing.

Fox, J. (1999) A ritual for our time in Gathering Voices: essays on playback theatre. New Paltz, New York: Tusitala Publishing.

Ivanhoe, P. (2009) Readings from the Lu-Wang School of Neo-Confucianism. Hackett Publishing Co.: Indianapolis, IN.

Jennings, S. (Ed.). (1995) Dramatherapy with children and adolescents. New York: Routledge

Johnson, E., \& O'Neill, C. (Eds.). (1984) Dorothy Heathcote: Collected writings on education and drama. London: Hutchinson.

Kim, Y. "Wang Yangming." Internet Encyclopedia of Philosophy. https://www.iep. utm.edu/ https://www.nytimes.com/2017/10/18/world/asia/china-guiyang-Wang Yangming-yangming-confucian.html.

McCaslin, N. (1980) Creative Drama in the Classroom and Beyond. 3 rd ed. New York: Longman.

McCaslin, N. (1987) Creative Drama in the Primary Grades: A Handbook for Teachers. New York: Longman.

McCaslin, N. (2000) Creative Drama in the Classroom and Beyond. 7 th ed. New York: Longman.

Moreno, J.L. (1953) Who Shall Survive? Beacon, New York: Beacon House.

Moreno, J.L. (1977) Psychodrama Volume I. Beacon, NewYork: Beacon House.

Moreno, Z. T. et. al. (2000) Psychodrama, Surplus Reality and the Art of Healing. London: Routledge.

Nelson, L., \& Finnerman, L. (2006). Drama and the Adolescent Journey. Portsmouth, New Hampshire: Heinemann Drama.

O’Neill, C. (1995) Drama Worlds: A Framework for Process Drama. Portsmouth, NH: Heinemann. 
Rogers, N. (2000). The Creative Connection: Expressive Arts as Healing. Ross-on-Wye, UK: PCCs Books.

Rogers, N. (2004). Expressive Arts for Peace: Using the Creative Process to Connect to the World (Temenos, Producer). [DvD]. Available from Temenos, 55 Westbourne Road, Sheffield S1O 2QT, UK.

Rogers, N. (2011) The Creative Connection for Groups: Person-Centered Expressive Arts for Healing and Social Change. Palo Alto, CA: Science and Behavior Books.

Schattner, G., \& Courtney, R. (Eds.). (1981) Drama in Therapy, Volume One: Children. New York: Drama Book Specialists.

Schön, D. (1983) The Reflective Practitioner: How Professionals Think in Action. New York: Basic-Books, Inc.

Slade, P. (1954) Child Drama. London: University of London Press.

Subbiondo, J. (2006) Integrating Religion and Spirituality in Higher Education: Meeting the global challenges of the 21st Century. Religion and Education 33: 20-38

Van Norden, Bryan. (2019) Stanford Encyclopedia of Philosophy. Friday July 11, 2014; revised Friday September 6, 2019. Accessed on January 20, 2020.

Way, Brian. (1967) Development Through Drama. London: Longman.

Winnicott, D.W. (1964) The Child, the Family, and the Outside World. New York: Perseus.

Winnicott, D. W. (1971) Playing and Reality. London: Routledge.

Yang-Ming, Wang, \& Chan, W. (Trans). (1963) Instructions for Practical Living and Other Neo-Confucian Writings. New York: Columbia University Press. 
